\section{Reflections on work in the contemporary context of the creative economy}

\author{
Reflexões sobre o trabalho no contexto contemporâneo da \\ economia criativa
}

Gislene Feiten Haubrich ${ }^{\mathrm{a}}$

Vânia Gisele Bessia

Maria Cristina Bohnenberger ${ }^{\mathrm{a}}$

Ernani Cesar de Freitas

a Universidade Feevale, Nova Hamburgo, RS, Brazil

b Universidade de Passo Fundo, Passo Fundo, RS, Brazil
Revista Organizações \& Sociedade 2020, 27(93), 255-267

(C) The Author(s) 2020

DOI 10.1590/1984-9270935

ISSN 1984-9230

www.revistaoes.ufba.br

NPGA, Escola de Administração

Universidade Federal da Bahia

Recebido: 17/11/2017 Aprovado: 10/05/2019

\begin{abstract}
This article aims to reflect upon the concept of work in the field of creative economy, as well as its contribution to the understanding of the culture of these kinds of organizations in the contemporary context. It is an exploratory study, based on bibliographic and documentary research. The theoretical framework is grounded on the notions of work, with emphasis on immaterial work (Lazzarato \& Negri, 2001; Schwartz \& Durrive, 2015), rhizome (Deleuze \& Guattari, 2000) and symbolic power (Bourdieu, 2002) to reflect on the context of creative economy (Florida, 2011; Howkins, 2013). As a main result of this initial reflection, it is understood that the interactions that are expected for and by creative economy workers move between a rhizomatic and libertarian perspective and a structural one based on shared values. In this case, organizations assume a different configuration through the culture expressed by norms and symbolic disputes, incorporated by each group in the conduct of their projects.
\end{abstract}

Keywords: Work; Creative Economy; Culture; Rhizome; Symbolic Power.

\title{
Resumo
}

Este artigo objetiva refletir sobre a concepção de trabalho no campo da Economia Criativa, bem como sobre a contribuição de tal conceito para o entendimento da cultura em organizações no contexto contemporâneo. Refere-se a uma pesquisa exploratória de cunho bibliográfico e documental. O marco teórico tem como base as noções de trabalho, com ênfase no trabalho imaterial (Lazzarato \& Negri, 2001; Schwartz \& Durrive, 2015), rizoma (Deleuze \& Guattari, 2000) e poder simbólico (Bourdieu, 2002) para refletir o contexto da Economia Criativa (Florida, 2011; Howkins, 2013). Como resultado principal desta reflexão teórica inicial, compreende-se que as interações pretendidas para e por trabalhadores da Economia Criativa transitam entre uma perspectiva rizomática e libertária e outra estrutural e baseada nos valores compartilhados. Nesse caso, as organizações assumem uma configuração diferenciada mediante a cultura expressa por normas e disputas simbólicas, incorporadas por cada grupo na condução de seus projetos.

Palavras-chave: Trabalho; Economia Criativa; Cultura; Rizoma; Poder Simbólico. 


\section{Introduction}

The working class has progressed overtime and, especially in the past decades, it underwent major transformation with the arrival of new activities and professions that demand different attitudes and relationships among peers. This is the case for the activities that compose the creative economy, which are especially anchored in the individuals' creative capabilities. Some examples of the activities embraced by this group of workers can be found under different categorizations, such as the United Nations Educational, Scientific and Cultural Organization (Unesco), Institute of Applied Economic Research (Ipea), and Industry Federation of the State of Rio de Janeiro (Firjan). Other activities worth mentioning are those related to culture, visual arts, cinema, music, fashion, gastronomy, marketing and publicity, and software development, among others.

Studies on the creative economy are not abundant. This, however, does not mean some contradictions cannot arise and, with it, the dialectical generation of new pieces of knowledge, necessary to both science and epistemology. Those who have studied the topic describe work in the creative economy as distinctive, the individuals more independent and connected to networks different from those established in either the post- or neo-Fordist industrial perspectives. In such networks, the workers would be connected to a structure and a set of rules established in a strict, bureaucratic and hierarchical way.

This paper reflects on this configuration between work and workers, and tries to understand if such relationships are, in fact, different: that is, if the structural bonds that pertain to the organizational models of work would effectively have different characteristics. From these initial forces, the study's guiding question is established: how does the concept of work in the creative economy field contribute to the reflection on the organizations' culture in the contemporary context? As a research assumption, the scientific discourse on work in the creative economy tend to address changes in the individuals' behaviors, as well as in the connections established for labor, which shows that the culture that connects these workers can be noticed before a constant mobilization between the rhizomatic and the structural perspective.

This article tries to reflect on the notion of work in the creative economy and its contribution to understanding the organizations' culture in this context. In this sense, this is an exploratory research developed based on scientific literature about the creative economy, with emphasis on Howkins (2013), Florida (2011), and reports produced by Unesco, Ipea and Firjan. Methodologically, this is a bibliographical and documental research. Besides the scientific discourse mentioned, the theoretical framework is represented by notions of immaterial work developed by Lazzarato and Negri (2001), and by labor activity from the perspective of Schwartz (2015). Then, the works of Deleuze and Guatarri (2000) and Bourdieu (2002) lead the discussion on the organizations' culture.

Besides the final considerations, the article is divided into three parts. First, the contemporary work context is reflected upon by considering the models of work organization and their changes overtime. This contextualization is complemented by an approach to labor based on the workers' point of view as well as from two distinct perspectives: immateriality and human activity, which embrace the focus on subjectivity and temporal imbrication, supporting the relationships between the individuals, their undertakings and production structures. The investigation is carried on with the recovery of scientific discourse produced about the creative economy field. Then, it is possible to move on towards the connection between the rhizome ideas and structure, whose basis holds the way of work in the creative context previously founded, and supports the final session of the article that combines the preliminary intermingling about clues to reflect upon the organizations and their cultural bases in contexts where work is a protagonist. 


\section{Rhizomatic capitalism, network society or control society? By way of [some] definitions about the contemporary society}

The history of humankind is marked by several events culminating in major changes to life on the planet. From natural catastrophes to those caused by the exercise of power and domination attempts, secular knowledge has shared room with transgression initiatives of a chaotic situation over another one summarily different. In this case, the content of social evolution is not fully linked to its indicative sense: development or gradual transformation ${ }^{1}$. Progress is gradually followed in different world locations; Africa and the Americas certainly share different dimensions of reality.

On the other hand, the digression about globalization or internationalization is still valid, even after the turn of the century [and of the millennium!]. However, the theme is examined differently. In the 2000s, the focus shifted a futuristic discourse, filled with optimism, to one that claimed total devastation almost twenty years later. There is a partial agreement on the difficulty manifested by the possibility of living through diversity and coexistence. In this case, it is possible to relate to the reflection by Pelbart (2003) about rhizomatic capitalism. Based on the work of sociologists Ève Chiapello and Luc Boltanski, "The new spirit of capitalism", Pelbart creates his narrative by including the events that come from the weakening of capitalism in the post-war period, such as May 68 in France, and the emergency of the Toyotist model of production, as opposed to Taylorism.

Among the several topics pointed out by Pelbart (2003), it is worth mentioning feedback and the reappearance of a stronger capitalism, latent manifestations that assimilates the individuals' demands to benefit from it. This author catalogues different aspects instituting what he calls neo-management: mobility encouragement, teamwork, openness and flexibility, adaptation "and each project is an opportunity to enrichen one's own competencies and increase employability" (p. 98). A new capitalism normativeness is established, which is no longer controlled by the employer, and promotes the possibility of self-control; the creation of value, which used to come from the company, is, then, understood from the conjunction of elements in a productive territory. The current management practices would be expanding their control over the individuals as they are discharged from their autonomy on behalf of a project which would supposedly be theirs (Gaulejac, 2005).

Although Pelbart (2003) emphasizes the incorporation aspects to capitalism, which culminated in this system's own update, he also highlights the process of production of such adjustment and promotes the notion of a networked, connectionist, rhizomatic capitalism. In this sense, as a reaction to the movements of refusal to society's hierarchic and bureaucratic way, which is characterized by the Taylorist operating way, there is the establishment of a logic of a "more flexible, undulating and open operation, with less defined boundaries and more multiple connections; in short, they are more rhizomatic" (p. 97).

Even though these issues' suitable procedures involve a process of social reorganization, that is, the review and recycling of structures (and, in this case, the concept of rhizome withers away ${ }^{2}$ ), the main point of the author's reflection is to perceive the movement, the power that is present in the escape lines, on the value attributed to what could be simplified as schizophrenic upon conception.

Upon explaining the meaning of networks in the social amplitude in their definition, Castells (2006) asserts that they "are open structures which develop by adding or removing nodes according to the programs' necessary changes that are able to reach the performance objectives for the network" (p. 20). At this point, Castells mentions the opportunity of control transgression, which is aimed at and encouraged by the centralizing structures that coexist with the contemporary universe along the networks. It should be noted that the opportunities of the individuals working in reducing the power of secular structures, such as the State or the Church, undergo these foundations, even before the expansion of the surveillance plans, punishment and reflexive imprisonment. In this case, the proposition of a rhizomatic look to society, according to the analysis

1. "Evolution", in Priberam Dictionary of Portuguese Language [online], 2008-2013. Retrieved from http://bit.ly/20WLdqi

2. As it will be shown later, the idea of rhizome is not linked to a fixed structure. 
by Deleuze and Guattari (2000), becomes interesting in order to reflect about the aspiration of an escape from the "control society", according to the conception by Deleuze (2004).

Thus, according to Castells' proposition, even if the network illustration does not fully represent the rhizome perspective, it converges to the production of nodes without a pre-defined direction, originated from the interactions instilled by the different items that make it. The rhizome by Deleuze and Guattari (2000) has neither subject nor object; it is combined from outlines that develop according to the connections. Keeping the differences in the historical point of view is something mutual: from the possibility of movement to the point beyond prediction; from that which is square but keeps the right of bond according to the situation and the proximity. Concerning the clues given by Pelbart, Castells, Deleuze and Guattari that project the possibility of comprehension of some of the realities that make up globalized daily life; this reality is produced by the ideological sphere that boosts the notion of creative economy.

It can be deduced that such ideological sphere is related to what Bourdieu (2003) defines as habitus. According to this author, "we can only explain the practices if we relate them to the objective structure that defines the social conditions of habitus production (which engineered these practices), to the conditions of exercise of this habitus, that is, to the scenario" (p. 58). The symbolic power (Bourdieu, 2002), which is invisible and practiced by either an agent or by a social layer as an unquestionable event, works as an engine to generate habitus before the interactions between the dominating agent and the dominated one. It is understood that, through the exercise of the symbolic power, individuals can be led and kept as the dominated ones, even if their bodies bear subversive signs. Facing the restriction of reaction based on the exercise of symbolic or physical violence, one wishes to wipe off such desire by keeping it devoid of any remembrance. Thus, work resignification is recognized and defended, which supports the fundamentally important human dimension, and the real possibility of social transformation by recognizing the individual's action potential.

This perspective can be assumed given the multiple changes that come from the conception of the creative economy field, which has been bursting in Australia and Great Britain since the 2000s and had its apex at the 2008 international crisis. Going deeper into these issues, the influence of such ideas is important to the constitution of workspaces. Among the relevant events in such process, there are the gains in autonomy that workers in the 1960s and 1970s aimed for, the Toyotist process, which includes elements considered human to the organizations' environments, as well as other stimuli developed along the 1980s and the 1990s, such as the interweaving of local, global and organizational culture. It can be supposed that these aspects produce changes as for "what" and "how" people expect to perform their activities, oftentimes trying to transgress the context imposed by social structures. It is in this scope that the conception by Florida (2011) makes sense:

In order to understand all these changes, it is necessary to rethink them as part of a global transformation that is intertwined with a single transformation that affects all the aspects of life. This transformation is nothing but the transition to an economic and social system that is based on human creativity. Most people have no idea that the changes in preferences related to work, lifestyle and community can be produced by such basic economic changes. This is my view. (p. 15)

The scientific discourse about work on the creative economy tend to address the changes in the individuals' behaviors, as well as in the connections established for the accomplishment of labor, which shows that the culture that gathers these workers can be noticed before a constant mobilization between the rhizomatic and the structural perspective. To these individuals, this would configure a space-time of work that is different from the one known to the industrial societies. This reflection follows this path by addressing these new possibilities of work in the contemporary context. 


\section{Immateriality in the drama exercise of using corps-soi}

Upon developing this study's initial reflections, we aim to embrace the central concepts in order to understand the relevance of the workers' demands in the development of the ways of contemporary interactions, which is inherent to the network dynamics mediated by technology. Even if this relationship is not obvious, it is inevitable. Over the course of the second half of the 20th century, mobilization for better work conditions occurred; with varied success, the theme was put under discussion in several locations around the globe. In this sense, the influence of the evolution of message dissemination was crucial to trigger global ideas related to disposal, exploration and search for dignity at work.

In the contemporary scenario, different discussions involve the issue of work in order to consider the organizations and, essentially, the collective existence. Work instructs society and this has been noticed since ancient times. Among the current viewpoints, there might be a dialogue between the immaterial perspectives (Lazzarato \& Negri, 2001) and the human activity of work (Schwartz, 2015), at least in regards to an initial proposition, since there are meaningful differences between the two perspectives. In any case, the approach begins. This choice comes from a basic contradiction between these two perspectives, but one that can be interesting in order to understand work in the creative economy context. While the immaterial work thinkers (Lazzarato \& Negri, 2001) consider the management changes as a study assumption that focuses on the fact that "personality, [worker's] subjectivity, must be organized and controlled" (p. 25), the ergologists defend a view turned to work as a human activity, such as the drama interactions of the self uses boosted by the corps-soi (Schwartz, 2015).

The path to understanding the labor and social reorganization changes in the current context is by definition taken by conventions, such as "post-industrial society", "post-modern society", "knowledge society", "network society". But this "poly-terminology" manifests the intention of structure production and foundations for some moves which can lead to what is presented as path multiplicity. In this sense, all these definitions have value dematerialization as a central point, which means the production focused on what is intangible, on information and on the expertise to establish connections to them. Over this work subjectivity value reference lays the immaterial work concept.

Lazzarato and Negri (2001) assert that immaterial work concept is characterized by its impossibility to be surrounded by time. What is the working time? What is the production time? What is the free time? These three temporal modalities mix with immaterial work, whose raw material is the individuals' subjectivity which conducts them and establishes new ways of exploration and accumulation relationships. In this case, these authors contribute to the notes by Pelbart (2003) about the innovating force of capitalism, which is nurtured from a critical moment before the defiance of the interlacing between autonomy and heteronomy, freedom and exploration, subjectivity and objectivity (Lazzarato \& Negri, 2001).

In this case, it is interesting to point out that the paradox that sets up, without the awareness of the workers, who searched for self-control, (always limited) freedom, and the possibility to create and praise their subjectivity, as opposed to the Taylorist control. Under a lose adaptation from capitalism, the immaterial work produces the Taylorist homogenization and rationale. Somehow, it goes on, since it is not about ending the material work, but adding it to the immaterial components, which is specific to the individual at work. The creative economy work has a narrow bond with the immaterial work, as described by Lazzarato and Negri (2001), and Lazzarato (2004), since, in their foundation, they have the subjectivity and the creativity of those who produce it.

In the audiovisual production, taken here as an example of the creative economy, a high intellectual and subjective investment is done by the team of workers who dedicate time to it. However, does the payment extend this process? How far will the workers involved see themselves as autonomous? Does mass dissemination peak the film commodities' production at times? The immaterial work perspective is a production from the reflection it intends to be, as it points out to a series of questions. But how far will it contribute to 
what it testifies as urgent? "The crisis about 'work value', which is also a capitalism crisis, would enable the foundation of the 'social relationship' over an 'alterity' in the market relationships in the capitalist branch" (Lazzarato \& Negri, 2001, p. 73).

It is based on this view that the interventions by Schwartz $(2014,2015)$ and Schwartz and Durrive (2015) can contribute to the reflection of work over creative economy, since they start from the human labor activity. In a certain way, it is connected to the Marxian complaint about the possibility of escape from strangeness of the worker's self-work. In this sense, it is similar to the concept of immaterial work, since Lazzarato and Negri (2001) set off from Marx to expand their work category. However, the perspective by Schwartz $(2014,2015)$ and Schwartz and Durrive (2015) moves away from many of the aspects drawn up by Marx, not by denying the capitalist system and promoting another political-economic system, but because its core is in the anthropological view about work and worker. As an activity, work is produced in unrepeatable situations before a process of choice appreciation and norm interpretations (about tasks and about team), and produces renormalizations, a constant path to innovation (Schwartz \& Durrive, 2015).

The choices this worker makes signify values and knowledge, and develop the subjectivity of their producer. Although there is work appreciation, its main contribution is the collective and the individual development before the exercise of an activity. In this sense, Schwartz (2014) focuses on the fact of using the term corps-soi to refer to this worker: "this way it would be possible to see the term corps-soi as a whole with an "active" confrontation with a social-ecological environment" (p. 265). Schwartz (2014) describes the worker as a corps-soi; that is, a being that promotes joint action between material and immaterial, a connection between soul and body in which managing the self-use comes from a triple anchoring: biological, historical and singular.

Therefore, this digression points to relevant views on the reflection about work, for, if on one hand the entrepreneurial practices encompassed the workers' demands over the past few decades and highlighted the problem about work value which comes from the human subjectivity, on the other hand many of these demands were re-signified and, so, affect the individuals' acritical point of view about their own actions. Which knowledge is tensioned? Which other forms of value, that are as subjective as the contemporary production, pervade the activity exercise? Which values boost the choices made by this corps-soi? How do these choices imply the relationships with alterity? Finally, it is possible to see that inter-relating these perspectives brings in several doubts, besides the ones previously discussed. However, they deal with key elements in order to understand this creative economy universe they refer to.

\section{Scientific discourse over work in creative economy}

Although several interpretations must be comprehended, especially in academia, the field of creative economy is confirmed in the world economic territory, even more in developed countries. Even if the numbers do not represent the most important view for the intended discussion, understanding this area's relevance for the Brazilian context means overriding through two aspects. The first, more obvious and popularized aspect, refers to the national GDP ${ }^{3}$ contribution. The Creative Industry Mapping, done by Firjan and which shows data from 2015, highlights that this area generated a GDP that is equivalent to R $\$ 155.6$ billion, or $2.64 \%$ of the national total. Comparing the 2013 index (Oliveira, Araujo \& Silva, 2013), there is a margin of growth around $0.2 \%$ in three years. Although this is not a high percentage, "the creative area proved to have little impact before the hostile 2013-2015 economic scenario when compared to the national economy totality" (Firjan, 2016, p. 6).

The second aspect refers to the number of people employed in this sector. This brief quantitative demonstration is necessary, since the debate over an economical proposal based on creativity needs numerical

3. Gross domestic product. 
elements in order to justify its attention. However, this is not the emphasis of the notes highlighted here, but the work in this context. Thus, it is worth mentioning that, in $2015,1.8 \%$ of the Brazilian population was dedicated to creative occupations (Firjan, 2016). This data refer to the employees in 13 creative sectors, according to their sectorial affinities in four major areas: Consumption (design, architecture, fashion and publicity), Media (editorial and audiovisual), Culture (heritage and arts, music, scenic arts and cultural expressions), and Technology (R\&D, biotechnology and ICT). Since they have characteristics that are similar to those in their sectors, this grouping enables reading the movements and the identification of the tendencies from the creative professionals, no matter where they work, whether in strictly creative companies or in any other economic activity, even those named as a traditional industry.

According to a study carried out by Foundation of Economics and Statistics in the state of Rio Grande do Sul (FEE) and disclosed by Creative Economy Observatory (Obec) ${ }^{4}$, in the Brazilian state of Rio Grande do Sul, "from the total of activities selected as the core of creative industries, the formal employments generated by the state of Rio Grande do Sul represent $5.8 \%$ of the national total, which means more than 74 thousand work positions" (Valiati \& Wink, 2013, p. 8). The numbers are persuasive, but who are these workers? What mobilizes them into this field of work? This information still needs to be structured all over the country. As for now, it is necessary to have the international production as a foundation for the topic.

This reality is noticed both in the Brazilian reports' analysis summary (Firjan, FEE/Obec, Ipea), which, for instance, reproduces the different models of characterization and classification in creative economy, according to the 2012 United Nations Conference on Trade and Development (Unctad) report. Although there is an understanding that there is need for data (considering its shortage) in a continental-size country such as Brazil, and also because a starting point is necessary, it is suggested by the baseline report, "therefore, the next border for the generation of knowledge involves the understanding of local levels about the interactions, specificities, policies and how the creative economy can be practically promoted in the communities, towns and regions through world development" (United Nations Development Programme \& Unesco, 2013, p. 154). Overall, while this data is not available, concepts from other areas dock the point of view cast over the issue.

This is the case of the handbook designed by British consultant and journalist John Howkins (2013), to which the first, more thorough investigation on the topic is attributed. To this author, creative economy "consists of the transactions within creative products. Each transaction may have two complementary values: the value of intangible, intellectual property and the value of the physical carrier or platform" (p. 17). Through this, it is possible to see that this author's focus is on the monetary issue of creativity use, whereas he defends the concept of "creative capital" as a fixed asset, since it is the result of an investment, presents essential qualities and refers to an input for creativity in the future.

From another perspective, Florida (2011) tries to reflect on the behavior of what he calls creative class. According to this author, the professionals from this class are driven by changes concerning values, norms and attitudes. From these changes, he highlights individuality, meritocracy, diversity and openness. The definition by Florida describes the creative class based on two components: (1) the Hyper-creative Center, composed of workers whose focus is the generation of new forms and contents; and (2) the creative professionals, who develop a highly intellectualized work for specific services. Although the concept by Florida can be classified as optimistic (which is not a problem) it depicts a well-located scenario that may not embrace the different realities lived by creative professionals, and even the different areas and activities embraced by the classifications.

Moreover, some explanations suggested by Florida (2011) are very contradictory. For example, there is the choice for the apparel's symbolic topic. On his book, the author tells of a situation where individuals are seen wearing different clothes (from sneakers to shoes) during a meeting in a lawyer's office in Washington, D.C. To him, this picture testifies that "the new rule is progressing towards no rule, that is, to a rule of diversity

4. Located in the Federal University of Rio Grande do Sul. This act is part of the complex planned by the 2012-2014 Creative Economy Plan. 
and tolerance" (p. 120). Later on, the author ensures: "this is directly related to the focus on creativity and to the demands of the creative class, which requires working with flexibility and expressing their identity through their looks" (p. 120, emphasis added).

Diversity and tolerance are associated to the creative workers' dressing code (which means accepting suits and/or shorts), since it is through clothing that the creative classes express their identity. However, it is interesting to note that, upon mentioning a code that involves identity recognition, that is, peers, the argument referring to tolerance and diversity is jeopardized. This may be because Louis Vuitton shoes and Havaianas flip-flops do not share the same symbolic (identity) universe simultaneously. In this case, it may be right to question if the word diversity should be updated, or even which diversity is being referred to. If the language is limited, it is intriguing to remember that the human being is characterized by the competence to produce and understand languages.

This way, it is possible to see that a series of paradoxes pervades the different notions related to the creative economy field, which is justified by its beginning, about twenty years ago in some developed countries; in Brazil, more effectively around four years ago. Such scenario is also connected to the context where it comes from, a society in search of definitions before its multiple branches and changes in the production ways, besides the production of inputs centered on information. In this sense, it is interesting to think that the different demonstrations on creative economy may be especially related to the creative power of a new reality, combined with several connection possibilities in a winding path. With the objective to think about this possible rhizomatic origin, especially from the perspective of Florida (2011), who emphasizes the human dimension in the changing process, the reflection goes on.

\section{Culture in the creative economy organizations: amongst the rhizomatic and structural perspectives}

Along the development of this reflection, whose focus is on work in the creative economy context, some clues stood out. From the multiple transformations in the modes of interaction and production to the innovation attempts, there is no doubt that this is leading towards a different scenario in relation to the current one. However, this movement is underway and will hardly reach a prodigious and extraordinary (provisory) conclusion, unless an alien nation descends to Earth and intelligent robots rise up. In either case, the collapse of humankind, as seen in apocalyptical, "nerd" movies, would be the generating factor for a total change. Since academic studies do not predict the elaboration of this type of research assumption, what it means is: depending on the individuals in society, holding cultural chains and facing such adverse social conditions, this transformation, more intensely speaking, will take centuries.

However, among the central elements of ideology that pervade the creative economy, there is the change of a cultural paradigm: from major companies to the connections established among individuals, from mere reproduction to creation, from individual to collective, among many other mobilizations, the fact its projection is not democratic is surprising. As Florida (2011) asserts, "along with the creative class there is a growing social group that I call service class. . . . On a major scale, the growth of the service class is an answer to the demands of the creative economy" (p. 71). To the workers who compose this secondary class there is the role of task servers to which the creative workers have no time nor desire. And, to these, the work conditions are assuredly much closer to Taylorism-Fordism, rejected by more critical theorists. Furthermore, this other contradiction, which is present in the Florida's work (for which another digression article would be necessary), there is the existence of at least two parallel universes in the creative economy context: one for the creatives and one for the servants.

In this case, upon considering the isolation between these two zones, whose intersection would happen only in consumption, a differentiated look can be given in order to understand the dynamics that the creative class longs for, as described by Florida (2011). The perspective by Deleuze and Guattari (2000) about rhizome is revealing; it goes beyond dealing with the "underground" thinking passages, from which little can 
be understood as a process, but combining their results before the cartography it produces, the rhizome show up as a place of unpredictability, deviations, secret, dispossessed paths.

Against the centered systems (and even the poly-centered ones), the hierarchical communication and pre-established connections, rhizome is a non-centered, non-hierarchical and non-significant system, without a General, without an organizing memory or central automaton, solely defined by a flow of circulation of states. (Deleuze \& Guattari, 2000, p. 32)

The rhizome metaphor is the perfect aim for the creative class: there are no bonds, no moments of pure creation, no irreprehensible movement, no structure-free construction. However, from this method, and facing the space-time frame in which it is inserted, it moves towards a utopia. In this case, through the stimulating rhizomatic proposal, there is the venture through an escape zone: rhizome, as a point of view about the world, a principle of innovation, able to branch beyond stipulation. The capital's suffocating structure strangles the being to the point they overflow and projects another path. In this sense, the proposal by Florida (2011) reaches "higher" levels and is seen as an escape route from the control system imposed by capitalism.

Adopting the rhizome view in the creative economy means breaking up with the structures that see work only as a means of capital production. Work becomes a way of expression that connects different subjects as they form a network. Information is in the network and the individual shares that which flows through the net; then, there is the agencying that carries several differences. "Agencying is precisely this dimension growth in a multiplicity that necessarily changes nature as its connections increase" (Deleuze \& Guattari, 2000 , p. 16). The capital, which is the line that connects escape routes, transforms its nature and is no longer a currency in order to become a connection.

In this case, there is no culture, but the lack of it, that is, the permanently changing movement. The concepts, the values and the stories are transfigured in multiple lines, which can either connect or not. Memory leaves the arborescent rationale and manifests as a mobility. "Short memory embraces forgetting as a process" (Deleuze \& Guattari, 2000, p. 25). Creation is a constant process that comes from the unconscious. The creative class, which is conducted by rhizomatic logic, experiments a constant circulation of states and permanent innovation. This rhizomatic cartography is the expression of what the creator expects. However, its comprehension is complex for the arborized brain cultivated through centuries in order to value the legacy and the memory. Moreover, it is cultivated by the capital for accumulation.

Once the perspective of rhizomatic capitalism is understood, as suggested by Deleuze and Guattari (2000), then "there is no universal capitalism and, in itself, capitalism exists in the crossroads of every kind of lineups, it is always neo-capitalism by nature, it turns its face for the worst both to the West and to the East, besides re-shifting the two" (p. 30). Capital is agencying. As an uninterrupted line, it crosses and allows itself going through multiple paths for its update. From another perspective, capitalism reinvents itself, since it is mobilized by a symbolic power, "this invisible power, which can only be exercised with the complicity of those who do not care if they are being subjected or even if they exercise it" (Bourdieu, 2002, p. 8). In this situation, the capitalist agencying is led by naturalized structures in the collective living, since they are hardly noticed, even unnoticed and/or ignored by their members.

If considered, these aspects allow supposing that the moment of passage from an arborescent logic to rhizomatic logic, such as the path suggested by the creative economy, demands a look through this interval. On one hand, it is necessary to recognize the existence of the social movements' sustaining pillars. On the other hand, it is important to agree that the movement happens and is triggered by a being that thinks and acts over this transformation. This being does not need to be one single individual but a subject who is composed of several others, of values incorporated along the trajectory and based on choices. These considerations contribute to the improvement of the dialogue between the notions of immaterial work (Lazzarato \& Negri, 2001) 
and the labor activity (Schwartz \& Durrive, 2015), for they mediate the comprehension of the transformations in the market relationships in the capitalist sphere.

Therefore, the social relationships are established through an alterity bond: to another one, composed of discourses and structures that are different from one's self. As this another one transforms the self, this self transforms the other one. This connection happens through values and interpretations which manifest the intellectual property's intangibility that is encompassed by work and which results in products or services. Innovation is associated to this process, which is a consequence of the re-normalizing competence of the workers' action upon exercising their labor activity. This way, and in order to understand the culture's intervention in this labor dynamics, which goes beyond evidencing something that the creative class aims at (the existence of a rhizomatic cartography), the contribution by Bourdieu (2002) is seen as fruitful. It is about the roles played both by the structures and by the agents, whose engendering is pervaded by a symbolic power.

The motivation to search for a point of view that embraces the structures that establish the collective comes from a citation by Florida (2011) about the identity aspects of the creative class, which is associated to the reflection on the surmised identity by Bourdieu (2002), which asserts: "existing is not only about being different but also about being legitimately recognized as different, which, in other words, means the real identity's existence assumes the real possibility, judicially and politically ensured, to officially point out the difference" (p. 129). In this sense, both the relevance attributed to apparel and the sign of emergency of a new class of workers due to the creative workers' role, represent their intention to state and the recognition before the others. If the focus is on sustaining through creative work without bonds of predefinitions, why and what is the reason this identity recognition is searched for? Why is there a need to officially self-state as different?

This aspect brings some thoughts on the symbolic relevance for the establishment of groups, their closure or openness. This note suggests that, in order to accomplish a project, the connections between the members of the creative class should rely on the values that they share. It is based on this possibility that the creative economy is recognized as a social field, that is, a multidimensional space of positions. "Any position can be defined due to a multidimensional system of coordinates whose values correspond to the values of the different pertinent variables" (Bourdieu, 2002, p. 135). Being part of the connection triggered by a project is related to the sharing of values that make the self-existence in other one's landscape.

Then, here is the suggestion that the organizations in the creative economy give using the most basic meaning of the term: arrangements based on the way that people with common (or partly common) points of view and purposes interact. The existence of certain norms that guide this interaction can be seen and they are bargained from symbolic disputes that are connected to the relationships between individuals whose ways of thinking and acting are mobilized by several values. This demonstration of norms and symbolic disputes allows recognizing each group's culture.

This comprehension is based on the three elements that compose the habitus explained by Bourdieu (2002): the structuring structures (subjectivity - the individual's action), the structured structures (objectivity social imposition) and the dominating instruments which imply the exercise of power, such as ideology.

\section{On the temporary impossibility of drawing conclusions about creative economy}

Multiple ideas were considered; the conclusions reached, however, are few. Some clues elicit unexpected diversions from the basilar line that structures the text. Would that be due to the way of thinking impressed by the rhizomatic encouragement? Would it be the need to edify structures in order to lead the thought? No matter the answer, it is believed this reflection contributes to illuminate a series of questions related to a field that is booming. On one hand, the appeal to the rhizome thought: "think outside of the box". On the other hand, the structural call: "do what the client wants", "do what the market demands". Situations that are sometimes seen as antagonistic are frequently experienced by creative economy professionals. It is 
impossible to look at the contemporary work scenario and not consider the paradoxes that became paradigms. Creative economy is centered in the possibility that these workers use all their creativity. It is possible, however, to see that structural chains are still limiting these creative processes.

Therefore, if the rhizomatic perspective allows comprehending the ideological construction that comes from the flow in connection lines, on the other hand the structural point of view follows the reflection on work changes and their implications to the organizations and their cultural demonstrations. This is because such perspective adds the different social structures and their investments, whose purpose, oftentimes, is to limit creative acts. Therefore, it is possible to see that the creative economy professionals still have not experienced the rhizomatic logic, since the rhizome does not follow structural logic. Will that be possible some day? In any case, when it comes to organizations in such context, which idea of organizational culture is being activated? Would these organizations effectively be different from those in the industrial, Taylorist-Fordist logic? Essentially speaking, what would be a creative organization? For now, it is impossible to reach conclusions about that. However, there is an ongoing analysis about a new productive dynamic, where the arrangements take place, usually under a widely differentiated perspective.

These considerations support the adoption of two ergological points of view and the immaterial work in order to understand the work representations conceived and reshaped by the individuals in their labor experience in the creative economy context. On one hand, with the ergologists, it is possible to move further into recognizing the mobilization of the situations and the mutual implications between environment and workers due to their choices at work. On the other hand, with the immaterial work thinkers, it is possible to recognize that this recognition is not, or will be, naïve, since the structural management bonds narrow the possibilities of the freed and autonomous subjective exercise that is the desire of some individuals. From the tension between these views, it is possible to move on into a different work perspective and into the organizations that come from it, since it recognizes and engages the individuals in the construction of a collective reality, as well as highlights the different norms and structures that are nourished and configured by collectivity. In this case, the liability for a social change undergoes both ends, between the individual and the collective, and vice-versa, in an uninterrupted and permanent movement.

Therefore, more than the organizations' culture, this essay addressed culture in the social context. This is justified by the work dynamics itself in the contemporaneity. Whether in major corporations or in co-working spaces, the search for "new" is permanent and the bond is no longer due to the corporation, but to the projects it suggests. The work teams can be temporary but the bonds that bring the professionals together in the search for a project's conclusion are always structured and structuring. In this sense, one can suspect that the creative economy workers aim for a wider and more diffuse legacy, since they see this multiplicity's relevance for the shaping of their point of view and, especially, of their values. It is, then, assumed that what binds the workers together into an organic network of work is the sharing of values and expectations about a certain result. Of course, these expectations also bring in uncertainty and instability. But what are these concepts, if not structures, whose meanings can be updated overtime?

\section{References}

Bourdieu, P. (2002). O poder simbólico. Rio de Janeiro, RJ: Bertrand Brasil.

Bourdieu, P. (2003). Esboço de uma teoria da prática. In R. Ortiz (Org.). A sociologia de Pierre Bourdieu (pp. 39-72). São Paulo, SP: Olho D'água.

Castells, M. (2006). A sociedade em rede: Do conhecimento à política. In M. Castells, \& G. Cardoso (Org.), A sociedade em rede: Do conhecimento à acção política (Debates Presidência da República, pp. 17-30). Lisboa: Imprensa Nacional.

Deleuze, G. (2004). Conversações: 1972-1990. São Paulo, SP: Editora 34. 
Deleuze, G., \& Guattari, F. (2000). Rizoma. In G. Deleuze, \& F. Guattari, Mil platôs: Capitalismo e esquizofrenia 2 (Vol. 1, pp. 10-36). São Paulo, SP: Editora 34.

Federação das Indústrias do Estado do Rio de Janeiro. (2014). Mapeamento da indústria criativa no Brasil. Retrieved from http://bit.ly/37ri50d

Federação das Indústrias do Estado do Rio de Janeiro. (2016). Mapeamento da indústria criativa no Brasil. Retrieved from http://bit.ly/37o7IAi

Florida, R. (2011). A ascensão da classe criativa: E seu papel na transformação do trabalho, do lazer, da comunidade e do cotidiano. Porto Alegre, RS: L\&PM Editores.

Gaulejac, V. (2005). La société malade de la gestion: Idéologie gestionnaire, pouvoir managérial et harcèlement social. Paris: Seuil.

Howkins, J. (2013). Economia criativa: Como ganhar dinheiro com ideias criativas. São Paulo, SP: M.Books.

Lazzarato, M. (2004). From capital-labour to capital-life. Ephemera, 4(3), 187-208. Retrieved from http://bit.ly/3bAXdr7

Lazzarato, M., \& Negri, A. (2001). Trabalho imaterial. Rio de Janeiro, RJ: DP\&A.

Oliveira, J. M., Araujo, B. C., \& Silva, L. V. (2013, outubro). Panorama da economia criativa no Brasil. Retrieved from http://bit.ly/322tZx7

Pelbart, P. (2003). Capitalismo rizomático. In P. Pelbart, Vida capital: Ensaios da biopolítica (pp. 96-106). São Paulo, SP: Iluminuras.

Schwartz, Y. (2014). Motivações do conceito de corpo-si. Letras de Hoje, 49(3), 259-274. doi: 10.15448/19847726.2014.3.19102

Schwartz, Y. (2015). L'activité peut-elle être objet d'“analyse"? Letras de Hoje, 50(suppl.), 42-52. doi:10.15448/1984-7726.2015.s.23138

Schwartz, Y., \& Durrive, L. (Orgs.). (2015). Trabalho e ergologia II: Diálogos sobre a atividade humana (Trabalho e Sociedade series). Belo Horizonte, MG: Fabrefactum.

United Nations Development Programme, \& United Nations Educational, Scientific and Cultural Organization. (2013). Creative economy report 2013: Special edition: Widening local development pathways. Retrieved from http://bit.ly/39vdFHw

Valiati, L. (Org.), \& Wink, M. V., Jr. (2013). Indústria criativa no Rio Grande do Sul: síntese teórica e evidências empíricas (2a ed.). Porto Alegre, RS: FEE. Retrieved from http://bit.ly/3bA7OIX

\section{Acknowledgements}

Coordenação de Aperfeiçoamento de Pessoal de Ensino Superior for the PhD fellowship 88887.176025/2018-00.

\section{About the Authors}

\section{Gislene Feiten Haubrich}

$\mathrm{PhD}$ in cultural expressions and process at Universidade Feevale and University of Strastbourg. Master of arts in cultural expressions and process by Universidade Feevale. E-mail: gisleneh@gmail.com. ORCID: 0000-0002-2849-0086 


\section{Vânia Gisele Bessi}

PhD in business administration at Universidade Federal do Rio Grande do Sul. Professor at Professional Master's Degree in Creative Industry at Universidade Feevale. E-mail: vania@feevale.br. ORCID: 0000-0002-0973-0961

\section{Maria Cristina Bohnenberger}

$\mathrm{PhD}$ in economics, organisation, and management at University of the Balearic Islands. Professor at Professional Master's Degree in Creative Industry at Universidade Feevale. E-mail: cristin@feevale.br. ORCID: 0000-0002-4018-1796

\section{Ernani Cesar de Freitas}

PhD with post-doctorate in applied linguistics and language studies at Pontifícia Universidade Católica de São Paulo. Professor at Graduate Program in Linguistics and Literature at Universidade de Passo Fundo. E-mail: ernanic@feevale.br. ORCID: 0000-0002-3290-3955 